Journal of Advanced Research in Fluid Mechanics and Thermal Sciences

\title{
Nano Bubble Lubrication for Flat Plates Skin Friction Reduction
}

\author{
Gunawan ${ }^{1,}$, Allessandro Setyo Anggito Utomo ${ }^{1}$, Yanuar $^{1}$ \\ 1 Department of Mechanical Engineering, Faculty of Engineering, Universitas Indonesia, Indonesia
}

\section{ARTICLE INFO}

\section{Article history:}

Received 29 September 2020

Received in revised form 5 February 2021

Accepted 10 February 2021

Available online 21 March 2021

\section{ABSTRACT}

The movement of the solution in a pipe is one of the determinants of resistance in the pipe. The resistance occurs due to the solution's movement with the pipe walls in different directions in its displacement. Then, the frictional force is generated due to these differences in movement. This results in an obstacle resulting in high-pressure drop due to a large amount of skin friction. So, in this research, we need a new method to reduce internal resistance in pipes. Before investigating the pipe's internal flow, this study wants to see its function and effect on the flat plate as an attempt to validate the investigations that will be carried out for future research efforts. The study aims to show the lubrication effect produced by using a $50 \mu \mathrm{m}$ bubble generated by a carbonceramic tube. The bubbles' injector distance ratio is 0.4 to 0.85 from the end of the plate. The power needed to produce the bubble is $2.2 \mathrm{~kW}$ on a plate with an area of $1 \times 10^{4} \mathrm{~mm}^{2}$. The reduction of skin friction was analyzed by capturing the shear stress that was reviewed using a load cell at fluid velocities at intervals of 1 to $20 \mathrm{~m} . \mathrm{s}^{-1}$ with a difference of $1 \mathrm{~m} \cdot \mathrm{s}^{-1}$. The results obtained in this study are that when the fluid velocity is at $7 \mathrm{~m} . \mathrm{s}^{-1}$ to $13 \mathrm{~m} . \mathrm{s}^{-1}$, the distribution of nanobubbles will increase. Moreover, a reduction in drag by \pm 60.5 percent, and the optimum skin friction $(\mathrm{Cv})$ ratio is at 0.4 to 0.6 .
Frictional force; skin friction; lubrication; drag reduction; nanobubbles

\section{Introduction}

Engineers in the past decade have contributed to the field of maritime research by investigating air lubrication techniques. The modern air lubrication method started with a study conducted by Sanders et al., [1], McCormick, and Bhattacharyya [2], which presented the first documentation about the reduction of drag using bubbles produced by electrolysis on a flat plate. The research opened the pathway for other investigation on the lubrication method using air bubbles. Gas injection within the boundary layer below the plate producing micro-scale lubrication conducted by Aljallis et al., [3] had shown that bubble injection could combat $\mathrm{CO}_{2}$ emissions. Research into boundary layer bubble injection forms a lubrication method used to reduce drag without endangering the environment, namely ALDR (Air Layer Drag Reduction). ALDR method was later tested by Laberteaux et al., [4] on model ships to examine further effects of bubbles on the boundary layer surface. The result had revealed that the ALDR technique or artificial air cavities could reduce

\footnotetext{
* Corresponding author.

E-mail address: gunawan_kapal@eng.ui.ac.id
}

https://doi.org/10.37934/arfmts.81.2.1424 
skin friction by $60-70 \%$. On the other hand, a different research on air lubrication method upon fullsized ships had been conducted by Deutsch et al., [5] and Kodama et al., [6].

The size of the bubbles will positively influence the lubrication method. Kawamura et al., [7] analyzed the bubble size effect by injecting air into a perforated plate. A $0.5 \mathrm{~mm}$ hole can produce foamed bubbles with a diameter of $0.01 \mathrm{~mm}$, provide more significant drag reduction compared to bubbles measuring $0.5 \mathrm{~mm}$ in diameter. Other research conducted by Yanuar et al., [8] displays 50 microns size bubbles, or ultrafine bubbles could mitigate skin friction by $8 \%$ depending on injection location. Yanuar et al., [8] recommends placing an ultrafine bubble injector in a ratio of 1:0.83 from the entire length of the vessel. However, Jang et al., [9] is concern about bubble injection as a lubrication method. Jang proposed that the power produced to generate the bubble is higher than the bubble effect to reduce drag.

In addition to the development of lubrication technology, research on drag reduction can be seen when examining boundary layers that exist on the surface of objects. Within the boundary layer, several things can influence the magnitude of the reduction in fluid resistance by the difference in fluid velocity and its interaction with the boundary layer that causes fluid return. Lenaers et al., [10] indicate a drag reduction by reducing skin friction by $12 \%$ to $18 \%$ as one of the possible factors. The same thing is indicated by turbulence fluid with a Reynold Number greater than 2500 in experiments conducted by Willert et al., [11]. Nonetheless, the reduction of skin friction is produced by the release of gas bubbles during turbulence. The advantages of cavitation bubbles become suitable for reducing friction resistance on the surface of objects.

Experimental research cannot be carried out in an open environment because of sound, light, waves, and pressure that affects bubble production. This effect was seen in the bubble bursts study due to atmospheric pressure of 0.01 to $0.1 \mathrm{MPa}$ by Lin P. et al., [12]. Of course, the experimental experiments in this manuscript aim to see the friction resistance conditions on the object's surface due to bubble injection on a flat plate. Continuing previous research by Yanuar et al., [8] so that others can analyze the results of the effects of nanobubble injection with similar studies by Madavan et al., [13], Kato et al., [14], Deutsch et al., [5], and Murai et al., [15] which shows a reduction in drag due to micro-bubble injection of a flat plate at fluid velocity (U) $1 \mathrm{~ms}^{-1}$ to $20 \mathrm{~ms}^{-1}$.

\section{Methodology}

\subsection{Experimental Analysis}

In this study, a mathematical model is used to measure the skin friction ratio. The mathematical model uses several assumptions, as suggested by Latorre et al., [16] and Webster [17]. Furthermore, the uncertainty in data collection reached $1.5 \%-2.5 \%$, due to the influence of sound contamination of 3-5\% and other external forces. Also, the following assumptions are applied.

i. The exposure model the total resistance produced $R_{T}=R_{n}+R_{p}$ with $V=$ constant.

ii. The effect of pressure on the resistance does not affect the flat plate because the experiment is proceeded in a containment unit with constant pressure. Hence, the subsequent assumptions occur $R_{n}=R_{p}$.

iii. $\quad \beta$, a result of comparison of $\frac{S_{n}}{S_{p}}$.

iv. The total of drag is $R_{T}=0.5 \times C f \times \rho S V^{2}$.

With some conditions that have been mentioned above we could now see the possibility of the emerging drag that produce by fluid flow using these mathematical expressions 


$$
R_{T o}=R_{n o}+R_{p o}
$$

The above states the total resistance on the surface of the flat plate without bubble injection to produce the overall of total resistance by the ratio of coated surface due to bubble production

$$
R_{T}=R_{n}+(1-\beta) R_{p o}+\beta\left(R_{p}\right)
$$

Therefor to simplify the mathematical expression of total resistance, we could proceed with subtractions ( 1 ) and (2) thus result in

$$
R_{T o}-R_{T}=\left(R_{n o}-R_{n}\right)+R_{p o}-(1-\beta) R_{p o}-\beta\left(R_{p}\right)
$$

Assuming the pressure resistance $R_{n}=R_{p}$, the total resistance can be expressed as $R_{T}=0.5 \times C f \times \rho S V^{2}$, the resulting mathematical equation could be seen as below

$$
\frac{R_{T o}-R_{T}}{C_{f o}}=0.5 \rho V^{2} \mathrm{~S}[[1-(1-\beta)]-\beta(\alpha)] ; \text { respect of } a=0.5 \rho S V^{2}
$$

By providing Eq. (4), we could simplify into the below equation

$$
\frac{R_{T o}-R_{T}}{C_{f o}}=a \beta-a \beta(\alpha)
$$

The skin friction coefficient relationship between 2 different situations namely the use of nano bubble injection methods and normal conditions, can be seen in the following equation

$$
\alpha=1-\left(\frac{R_{T o}-R_{T}}{C_{f o}(\mathrm{a} \beta)}\right)=\frac{C_{f}}{C_{f o}}
$$

Furthermore, the skin friction ratio is compared to the ratio of gas distribution or void fraction produced by turbulence under the flat plate. Turbulence occurs inside the boundary layer and is captured by the load cell in the form of sheer stress or tw as previously shown in a study by Yanuar et al., [8]. So, it can be expressed as follows

$$
C_{v}=\frac{Q_{a}}{Q_{a}+Q_{w}}
$$

where Qa acts as the volume of the gas flux and Qw as the boundary layer flow. All of the following mathematical terminology above is explained in the nomenclature. 


\subsection{Experimental Setup}

This research aims to produce a skin friction ratio to show the percentage of drag reduction based on the fluid's velocity by tap water with the characteristics of a density of $997 \mathrm{~kg} / \mathrm{m}^{3}$, fluid viscosity reaching $1.002 \mathrm{mPa}$.s, and a temperature of $20^{\circ} \mathrm{C}$. Furthermore, the experiment is influenced by two regions, namely the area where the experiment takes place and fluid circulation. Fluid circulation is carried out on pipes with a length of $1000 \mathrm{~mm}$ to $2500 \mathrm{~mm}$. The pipe's size that connects through the experimental tank is $6.3 \mathrm{~mm}$ and $11.8 \mathrm{~mm}$ in diameter. The pipe measurement is done with a micrometer and roll meter as a measuring instrument calibrated with an accuracy of 0.001 . A centrifugal water pump also aids fluid circulation with a constant rotation speed of $0.2 \mathrm{MPa}$. The pressure monitoring process is also assisted with a pressure gauge mounted above the water pump. The centrifugal water pump aims to fill the experimental tank and help expel air from the experimental tank. The expulsion of air from the experimental tank required 7 hours due to limited pump strength. The purpose of air discharges is that contamination by pressure differences cannot occur in the experimental tank. In Table 1, we can see details of the experimental components of the test environment of circulation and nanobubbles production.

Table 1

Nanobubble Drag Reduction System Details

\begin{tabular}{lll}
\hline NBDR system details & Unit & Main Hull \\
\hline Gas Pressure & Mpa & 0.2 \\
Gas Flux Injection Rate & $\mathrm{Qa}_{\left(\mathrm{m}^{3} / \mathrm{min}\right)}$ & 2.640 \\
Bubble Diameter & $\mathrm{d}_{\mathrm{b}}, \mathrm{mm}$ & 50 micron \\
Ejector total & - & 1 (35 mm in diameter) \\
Hole Diameter & $\mathrm{d}(\mathrm{mm})$ & 18 \\
Water Salinity & $\mathrm{ppt}$ & $0.5-1$ \\
Water Temperature & ${ }^{\circ} \mathrm{C}$ & 20 \\
Height & $\mathrm{h}_{a}(\mathrm{~mm})$ & 2000 \\
Width & $\mathrm{W}_{\mathrm{a}}(\mathrm{mm})$ & 500 \\
Length & $\mathrm{A}_{a}\left(\mathrm{~mm}^{2}\right)$ & 2000 \\
Distance from injector & $\mathrm{Xf}, \mathrm{m}$ & 0.06 \\
\hline
\end{tabular}

The research tank conducted with three steps experiment; First of all, filling the tank with tap water to carry out an analysis and inspection of the drag that occurs using 1 type of fluid as stated above and the investigation conducted through three different ranges of fluid flow speeds. The first condition is fluid velocity $1 \mathrm{~ms}^{-1}<U<6 \mathrm{~ms}^{-1}$ for the low-speed category, the second fluid velocity 7 $\mathrm{ms}^{-1}<U<13 \mathrm{~ms}^{-1}$ as the medium speed category, and $14 \mathrm{~ms}^{-1}<U<20 \mathrm{~ms}^{-1}$ with the high-speed category. For restricting additional gas effect, the experiment's tap water is vacuumed by a vacuum pump, 8 hours before conducting any experimental procedure. Water used after the trial session is disposed of from the test tank, left in a separate tank for 1 hour, and vacuumed before conducting another experiment. The piping system used can be seen clearly in Figure 1.

Finally, in the experiment stage, $50 \mu \mathrm{m}$ gas bubbles produced by gas flowed through the compressor, the size and method of bubble production have been carried out in previous experiments on the research by Yanuar et al., [8]. The injector used is a modification of a carbonceramic tube and a venturi pipe with a diameter of $18 \mathrm{~mm}$ to concentrate a stable gas distribution with a constant distribution speed of $11 \mathrm{~ms}^{-1}$. These specifications can be seen more clearly in Figure 2. During the gas distribution process as shown in Figure 3, the flat plate used is connected to a load cell with an SWCM $500 \mathrm{~g}$ type. The load cell captures shear stress along the flat plate produced during the lubrication process in Table 2. 


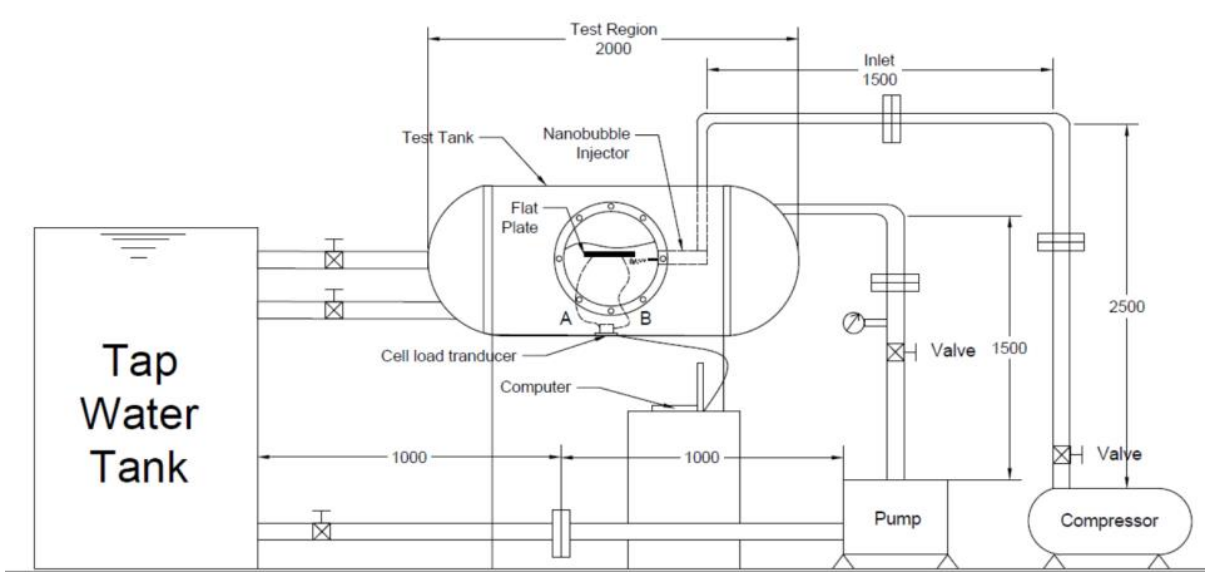

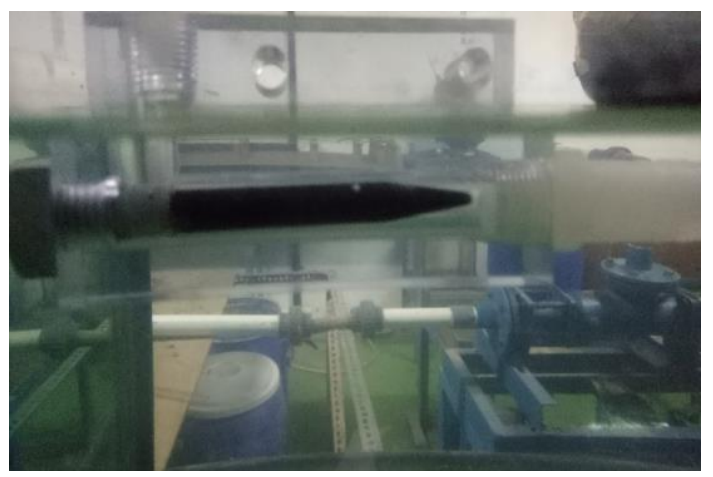

(b) (a)

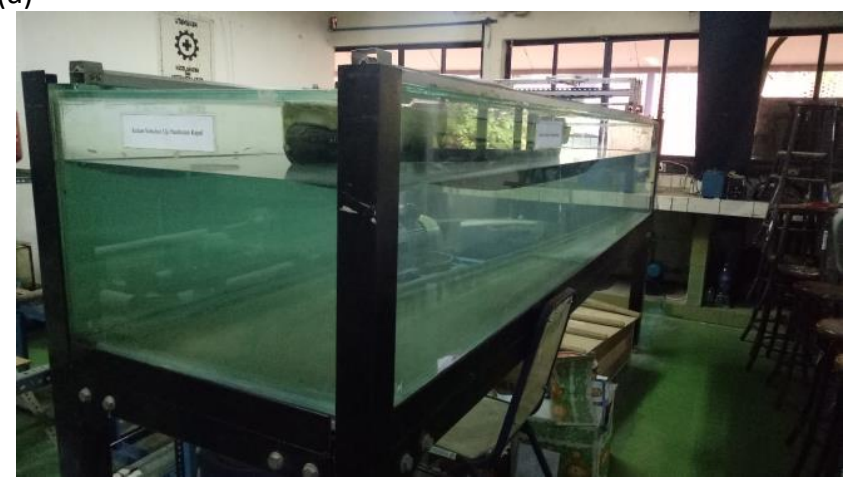

(c)

Fig. 1. Experimental of Nanobubble Distribution Pipeline System (a) Schematic for apparatus, (b) Bubble injector in distribution tank, (c) test tank

The data obtained is then processed by mathematical analysis to produce three graphs, which will be discussed in the next section. The three diagrams explain the correlation between the coefficient of skin friction and the ratio of nanobubble distribution or void fraction in 20 different fluid velocity. Another graph is showing the relationship between the percentages of drag reduction and nanobubble distribution ratio in respect of fluid flow velocity.

\section{Table 2}

Shear stress vs. Gas flow ratio

\begin{tabular}{lllllll}
\hline & & & & & & \\
\cline { 2 - 6 } $\mathrm{CV}$ & $\mathrm{U}=1 \mathrm{~m} / \mathrm{s}$ & $\mathrm{U}=2 \mathrm{~m} / \mathrm{s}$ & $\mathrm{U}=3 \mathrm{~m} / \mathrm{s}$ & $\mathrm{U}=4 \mathrm{~m} / \mathrm{s}$ & $\mathrm{U}=5 \mathrm{~m} / \mathrm{s}$ & $\mathrm{U}=6 \mathrm{~m} / \mathrm{s}$ \\
\hline 0 & 0,71668 & 2,04808 & 3,80076 & 5,88084 & 8,37988 & 11,62809 \\
0,1 & 0,68617 & 1,96270 & 3,64556 & 5,64313 & 8,05433 & 11,22351 \\
0,2 & 0,67039 & 1,91859 & 3,56543 & 5,52044 & 7,88651 & 11,01564 \\
0,3 & 0,65423 & 1,87344 & 3,48345 & 5,39496 & 7,71504 & 10,80379 \\
0,4 & 0,63767 & 1,82718 & 3,39950 & 5,26649 & 7,53968 & 10,58769 \\
0,5 & 0,64600 & 1,85045 & 3,44173 & 5,33111 & 7,62787 & 10,69628 \\
0,6 & 0,65423 & 1,87344 & 3,48345 & 5,39496 & 7,71504 & 10,80379 \\
0,7 & 0,67039 & 1,91859 & 3,56543 & 5,52044 & 7,88651 & 11,01564 \\
0,8 & 0,70159 & 2,00584 & 3,72397 & 5,76321 & 8,21872 & 11,52827 \\
0,9 & 0,71668 & 1,39580 & 3,80076 & 5,88084 & 8,37988 & 11,72705 \\
1 & 0,72410 & 2,06887 & 3,83858 & 5,93878 & 8,45932 & 11,82519 \\
\hline
\end{tabular}




\begin{tabular}{llllllll}
\hline & TW & \multicolumn{7}{c}{ CV } & $\mathrm{U}=7 \mathrm{~m} / \mathrm{s}$ & $\mathrm{U}=8 \mathrm{~m} / \mathrm{s}$ & $\mathrm{U}=9 \mathrm{~m} / \mathrm{s}$ & $\mathrm{U}=10 \mathrm{~m} / \mathrm{s}$ & $\mathrm{U}=11 \mathrm{~m} / \mathrm{s}$ & $\mathrm{U}=12 \mathrm{~m} / \mathrm{s}$ & $\mathrm{U}=13 \mathrm{~m} / \mathrm{s}$ \\
\hline 0 & 15,1457 & 18,9145 & 22,63569 & 26,91518 & 31,72713 & 36,74478 & 42,90454 \\
0,1 & 14,6531 & 18,32604 & 21,96386 & 26,14245 & 30,85515 & 35,76775 & 41,84164 \\
0,2 & 14,4004 & 18,0246 & 21,62012 & 25,74439 & 30,40642 & 35,26531 & 41,29584 \\
0,3 & 14,1432 & 17,71804 & 21,27082 & 25,34414 & 29,95552 & 34,76071 & 40,74827 \\
0,4 & 13,8813 & 17,40608 & 20,91569 & 24,93334 & 29,53944 & 34,29531 & 40,24376 \\
0,5 & 14,0129 & 17,56275 & 21,094 & 25,1406 & 29,77234 & 34,55578 & 40,52606 \\
0,6 & 14,1432 & 17,71804 & 21,32358 & 25,46346 & 30,11263 & 34,9365 & 40,93896 \\
0,7 & 14,4004 & 18,0246 & 21,63743 & 25,8241 & 30,54106 & 35,41604 & 41,45952 \\
0,8 & 15,0241 & 18,76912 & 22,51957 & 27,3507 & 32,26148 & 37,04797 & 43,23476 \\
0,9 & 15,2664 & 19,05878 & 22,81698 & 27,18111 & 32,04881 & 36,80755 & 42,97288 \\
1 & 15,3862 & 19,20198 & 23,01312 & 27,90856 & 32,89123 & 37,76004 & 44,01103 \\
\hline
\end{tabular}

\begin{tabular}{llllllll}
\hline \multicolumn{7}{c}{$\mathrm{TW}$} & \multicolumn{7}{l}{$\mathrm{l}$} \\
\hline $\mathrm{CV}$ & $\mathrm{U}=14 \mathrm{~m} / \mathrm{s}$ & $\mathrm{U}=15 \mathrm{~m} / \mathrm{s}$ & $\mathrm{U}=16 \mathrm{~m} / \mathrm{s}$ & $\mathrm{U}=17 \mathrm{~m} / \mathrm{s}$ & $\mathrm{U}=18 \mathrm{~m} / \mathrm{s}$ & $\mathrm{U}=19 \mathrm{~m} / \mathrm{s}$ & $\mathrm{U}=20 \mathrm{~m} / \mathrm{s}$ \\
\hline 0 & 44,8499 & 48,32549 & 54,0225 & 60,01264 & 64,92512 & 69,351 & 74,34669 \\
0,1 & 43,5776 & 46,87195 & 52,44518 & 58,31026 & 63,05681 & 67,29298 & 72,1071 \\
0,2 & 42,9224 & 46,12237 & 51,63234 & 57,43356 & 62,09435 & 66,23202 & 70,95212 \\
0,3 & 42,2638 & 45,36804 & 50,81478 & 56,5522 & 61,12653 & 65,1646 & 69,7898 \\
0,4 & 42,1803 & 45,27239 & 50,71114 & 56,4405 & 61,00386 & 65,02926 & 69,64241 \\
0,5 & 41,9961 & 45,06124 & 50,48238 & 56,19398 & 60,73312 & 64,73053 & 69,31705 \\
0,6 & 42,4933 & 45,63101 & 51,09974 & 56,85934 & 61,46383 & 65,53668 & 70,195 \\
0,7 & 43,1191 & 46,34739 & 51,87631 & 57,69666 & 62,38321 & 66,5505 & 71,29885 \\
0,8 & 42,7447 & 45,9189 & 51,41178 & 57,19574 & 62,31593 & 67,6846 & 72,53336 \\
0,9 & 44,9315 & 48,41869 & 54,12369 & 60,1219 & 65,045 & 69,12705 & 74,10304 \\
1 & 46,1696 & 49,83061 & 55,65724 & 61,77846 & 66,86225 & 71,13698 & 76,28944 \\
\hline
\end{tabular}

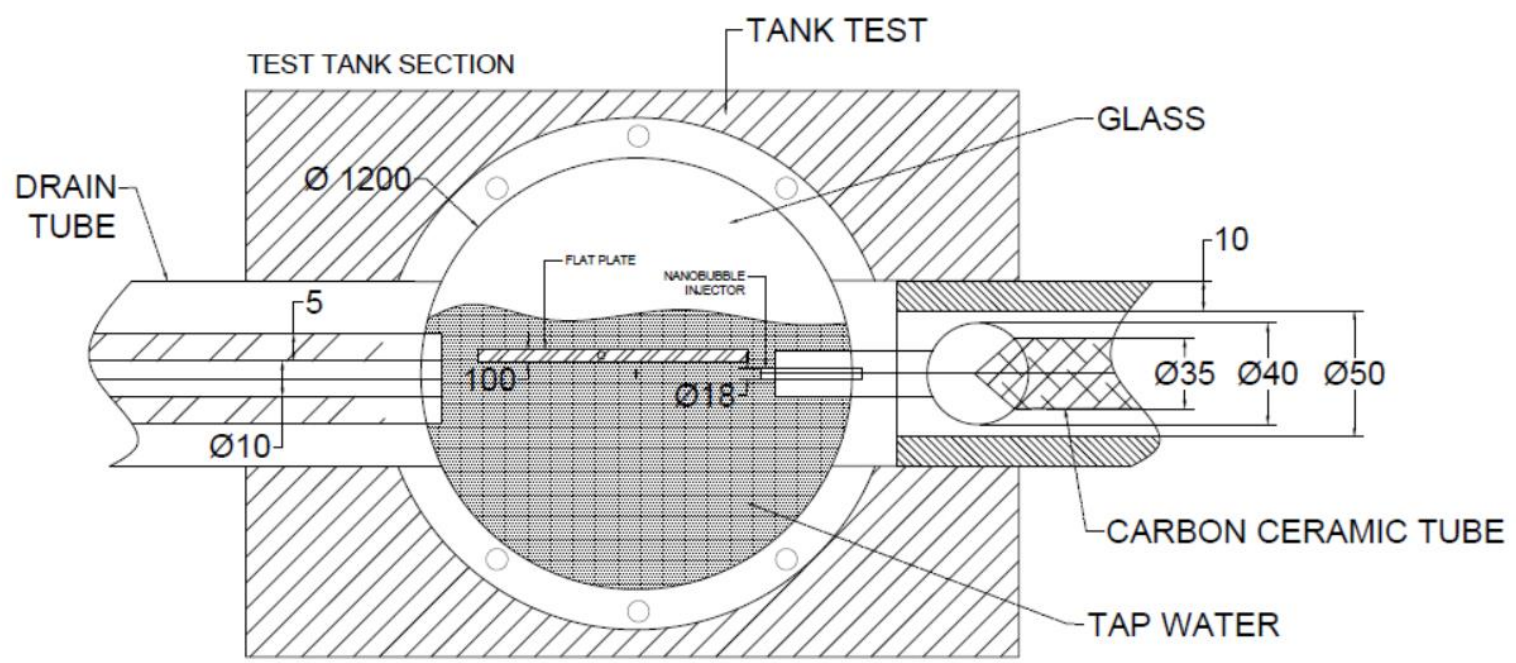

Fig. 2. Intersection of test tank section on nanobubble injector 

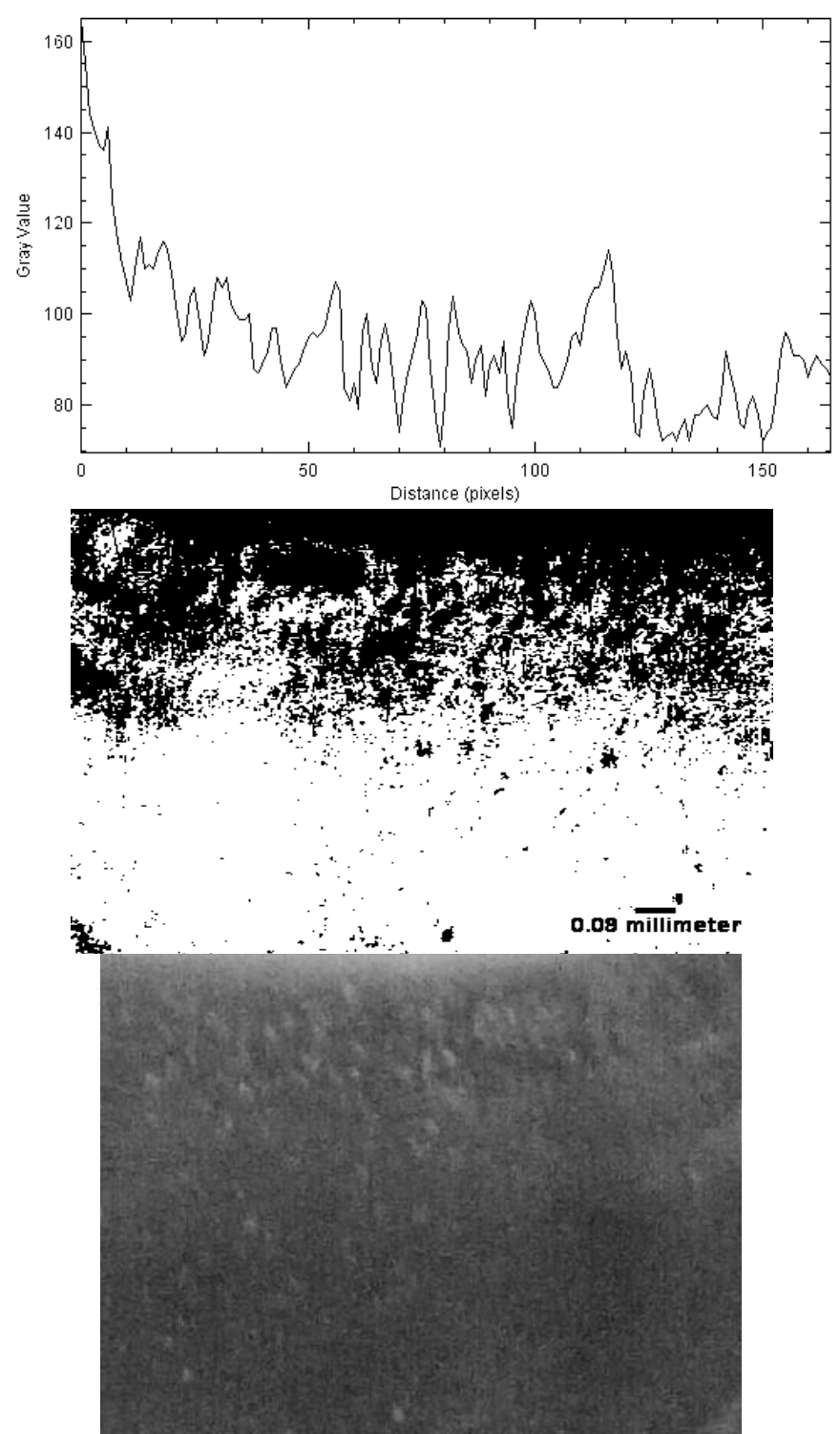

Fig. 3. Nanobubble Distribution below Flat Plates

\section{Results and Discussion}

Figure 4(a), 4(b), and 4(c) obtained from the gas distribution process in the carbon-ceramic tube. The material helps the entry of air in the boundary layer to form 50 micron-sized bubbles that go at a speed of $1 \mathrm{~ms}^{-1}<\mathrm{U}<20 \mathrm{~ms}^{-1}$. Previous research on bubble injection has been carried out by Madavan et al., [13], Kato et al., [14], Deutsch et al., [5], and Murai et al., [15]. In the discussion of the results of their research, it appears that the development of bubble injection research to reduce drag can be implemented in 3 ways, namely, reducing obstacles in the pipeline, the environmental development of marine life, and the lubrication system on ships. Based on Figure 4(a) shows that the fluid velocity affects the gas distribution ratio and the reduction of the skin friction coefficient ratio. It can be seen from Figure 4(a) that the effectiveness of the gas distribution ratio starts when the range of $0.0<\mathrm{Cv}<0.4$ decreases, this is due to the reduction in the gas distribution ratio which takes time to collect under the plate and serves as bubble lubrication in the boundary layer. The increase occurs when $\mathrm{Cv}$ is in the range of 0.5 to 1 ; this is because the gas distribution has expanded below the plate's surface. The actual parameter data measured from Figure 4 can be seen in Table 3 . 


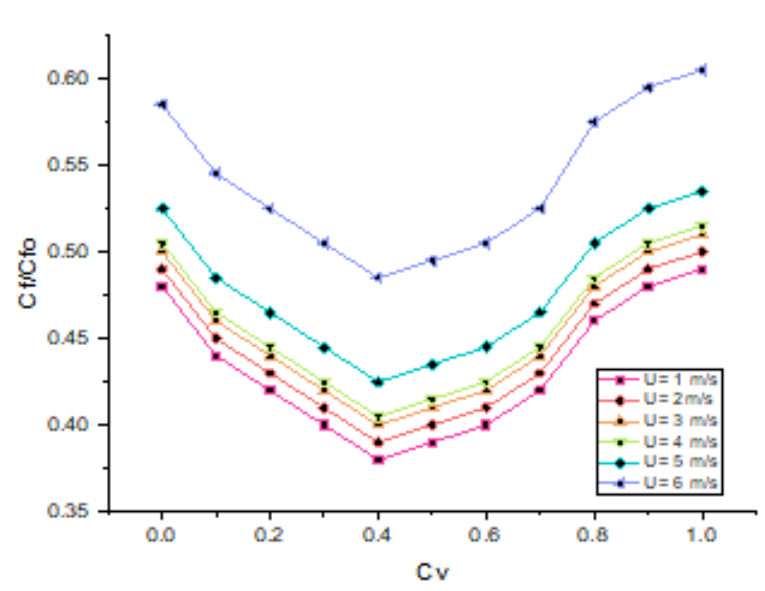

(a)

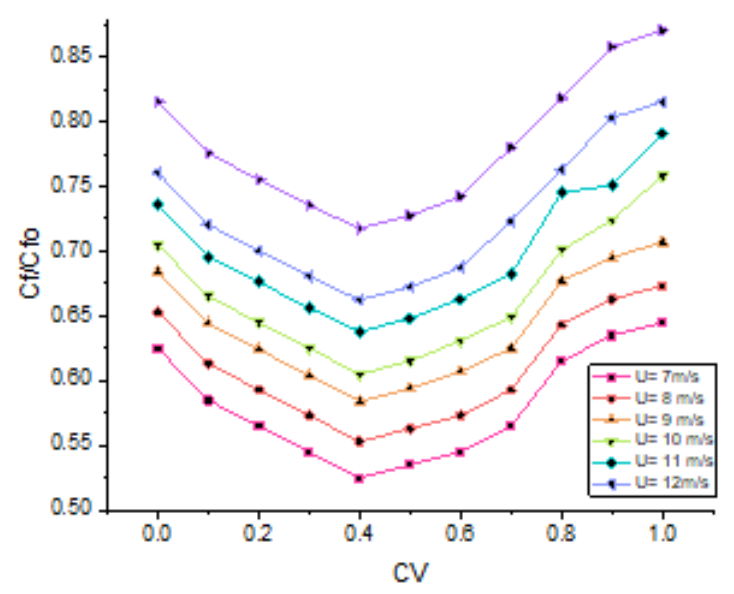

(b)

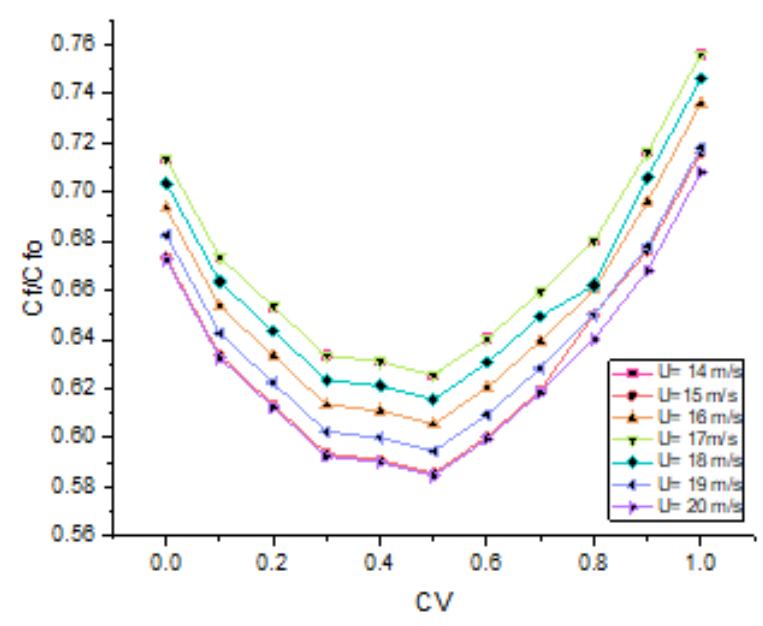

(c)

Fig. 4. The coefficient of skin friction and the ratio of nanobubble distribution. (a) fluid velocity $1 \mathrm{~ms}^{-1}<U<$ $6 \mathrm{~ms}^{-1}$. (b) $7 \mathrm{~ms}^{-1}<U<13 \mathrm{~ms}^{-1}$, and (c) $14 \mathrm{~ms}^{-1}<U<20 \mathrm{~ms}^{-1}$

However, it is not enough to add to the reduction in the skin friction ratio. The findings show that at that time, the bubble is fused with other bubbles. Resulting in the formation of micro-sized bubbles. So that when the fluid velocity is in the range of $1 \mathrm{~ms}^{-1}<\mathrm{U}<6 \mathrm{~ms}^{-1}$, the maximum drag reduction that can be obtained is $60.5 \%$, with a reduction in the skin friction ratio of 0.595 . Other results are seen in Figure 4(b), in contrast to fluid velocity shown by 4 a used in the range of $6 \mathrm{~ms}^{-1}<$ $\mathrm{U}<13 \mathrm{~ms}^{-1}$. In addition to the speed range, the difference is seen in the skin friction ratio reduction, which increased by $20.2 \%$. The decrease is because nanobubbles can spread even faster at that speed. Supported by the experiments of Yanuar et al., [8], this is due to the ratio of gas distribution to the speed and the distribution of bubbles in synchronous flow. Reckon we compared with a study by Murai et al., [15], which can only maintain the efficiency of drag reduction by $58 \%$ when reducing skin friction ratio is in the range of 0.2-0.4. At the same time, this study can maintain the reduction of skin friction in the range of $0.4-0.85$ with $2.2 \mathrm{~kW}$ power consumed by the pump. A drastic increase even though the fluid speed range is the same. Therefore, nanobubbles become more effective than microbubbles. 
Table 3

Measured data of skin friction coefficient on nanobubble drag reduction

\begin{tabular}{|c|c|c|c|c|c|c|c|c|c|c|}
\hline \multirow[b]{2}{*}{$\mathrm{CV}$} & \multicolumn{10}{|c|}{ Cf/Cfo } \\
\hline & $\begin{array}{l}\mathrm{U}=1 \\
\mathrm{~m} / \mathrm{s}\end{array}$ & $\begin{array}{l}\mathrm{U}=2 \\
\mathrm{~m} / \mathrm{s}\end{array}$ & $\begin{array}{l}\mathrm{U}=3 \\
\mathrm{~m} / \mathrm{s}\end{array}$ & $\begin{array}{l}\mathrm{U}=4 \\
\mathrm{~m} / \mathrm{s}\end{array}$ & $\begin{array}{l}\mathrm{U}=5 \\
\mathrm{~m} / \mathrm{s}\end{array}$ & $\begin{array}{l}\mathrm{U}=6 \\
\mathrm{~m} / \mathrm{s}\end{array}$ & $\begin{array}{l}\mathrm{U}= \\
7 \mathrm{~m} / \mathrm{s}\end{array}$ & $\begin{array}{l}\mathrm{U}=8 \\
\mathrm{~m} / \mathrm{s}\end{array}$ & $\begin{array}{l}\mathrm{U}=9 \\
\mathrm{~m} / \mathrm{s}\end{array}$ & $\begin{array}{l}\mathrm{U}=10 \\
\mathrm{~m} / \mathrm{s}\end{array}$ \\
\hline 0 & 0,48 & 0,49 & 0,5 & 0,505 & 0,525 & 0,585 & 0,625 & 0,653 & 0,684 & 0,705 \\
\hline 0,1 & 0,44 & 0,45 & 0,46 & 0,465 & 0,485 & 0,545 & 0,585 & 0,613 & 0,644 & 0,6651 \\
\hline 0,2 & 0,42 & 0,43 & 0,44 & 0,445 & 0,465 & 0,525 & 0,565 & 0,593 & 0,624 & 0,645 \\
\hline 0,3 & 0,4 & 0,41 & 0,42 & 0,425 & 0,445 & 0,505 & 0,545 & 0,573 & 0,604 & 0,6251 \\
\hline 0,4 & 0,38 & 0,39 & 0,4 & 0,405 & 0,425 & 0,485 & 0,525 & 0,553 & 0,584 & 0,605 \\
\hline 0,5 & 0,39 & 0,4 & 0,41 & 0,415 & 0,435 & 0,495 & 0,535 & 0,563 & 0,594 & 0,6151 \\
\hline 0,6 & 0,4 & 0,41 & 0,42 & 0,425 & 0,445 & 0,505 & 0,545 & 0,573 & 0,607 & 0,631 \\
\hline 0,7 & 0,42 & 0,43 & 0,44 & 0,445 & 0,465 & 0,525 & 0,565 & 0,593 & 0,625 & 0,649 \\
\hline 0,8 & 0,46 & 0,47 & 0,48 & 0,485 & 0,505 & 0,575 & 0,615 & 0,643 & 0,677 & 0,728 \\
\hline 0,9 & 0,48 & 0,49 & 0,5 & 0,505 & 0,525 & 0,595 & 0,635 & 0,663 & 0,695 & 0,719 \\
\hline \multirow[t]{2}{*}{1} & 0,49 & 0,5 & 0,51 & 0,515 & 0,535 & 0,605 & 0,645 & 0,673 & 0,707 & 0,758 \\
\hline & \multicolumn{10}{|l|}{ Cf/Cfo } \\
\hline CV & $\begin{array}{l}\mathrm{U}=11 \\
\mathrm{~m} / \mathrm{s}\end{array}$ & $\begin{array}{l}\mathrm{U}=12 \\
\mathrm{~m} / \mathrm{s}\end{array}$ & $\begin{array}{l}\mathrm{U}=13 \\
\mathrm{~m} / \mathrm{s}\end{array}$ & $\begin{array}{l}\mathrm{U}=14 \\
\mathrm{~m} / \mathrm{s}\end{array}$ & $\begin{array}{l}\mathrm{U}=15 \\
\mathrm{~m} / \mathrm{s}\end{array}$ & $\begin{array}{l}\mathrm{U}=16 \\
\mathrm{~m} / \mathrm{s}\end{array}$ & $\begin{array}{l}\mathrm{U}=17 \\
\mathrm{~m} / \mathrm{s}\end{array}$ & $\begin{array}{l}\mathrm{U}=18 \\
\mathrm{~m} / \mathrm{s}\end{array}$ & $\begin{array}{l}\mathrm{U}=19 \\
\mathrm{~m} / \mathrm{s}\end{array}$ & $\begin{array}{l}\mathrm{U}=20 \\
\mathrm{~m} / \mathrm{s}\end{array}$ \\
\hline 0 & 0,74 & 0,76 & 0,82 & 0,71 & 0,67 & 0,69 & 0,71 & 0,70 & 0,68 & 0,67 \\
\hline 0,1 & 0,70 & 0,72 & 0,78 & 0,67 & 0,63 & 0,65 & 0,67 & 0,66 & 0,64 & 0,63 \\
\hline 0,2 & 0,68 & 0,70 & 0,76 & 0,65 & 0,61 & 0,63 & 0,65 & 0,64 & 0,62 & 0,61 \\
\hline 0,3 & 0,66 & 0,68 & 0,74 & 0,63 & 0,59 & 0,61 & 0,63 & 0,62 & 0,60 & 0,59 \\
\hline 0,4 & 0,64 & 0,66 & 0,72 & 0,63 & 0,59 & 0,61 & 0,63 & 0,62 & 0,60 & 0,59 \\
\hline 0,5 & 0,65 & 0,67 & 0,73 & 0,63 & 0,59 & 0,61 & 0,63 & 0,62 & 0,59 & 0,58 \\
\hline 0,6 & 0,66 & 0,69 & 0,74 & 0,64 & 0,60 & 0,62 & 0,64 & 0,63 & 0,61 & 0,60 \\
\hline 0,7 & 0,68 & 0,71 & 0,76 & 0,66 & 0,62 & 0,64 & 0,66 & 0,65 & 0,63 & 0,62 \\
\hline 0,8 & 0,76 & 0,77 & 0,83 & 0,65 & 0,61 & 0,63 & 0,65 & 0,65 & 0,65 & 0,64 \\
\hline 0,9 & 0,75 & 0,76 & 0,82 & 0,72 & 0,68 & 0,70 & 0,72 & 0,71 & 0,68 & 0,67 \\
\hline 1 & 0,79 & 0,80 & 0,86 & 0,76 & 0,72 & 0,74 & 0,76 & 0,75 & 0,72 & 0,71 \\
\hline
\end{tabular}

Nevertheless, this is caused by different bubble characteristics. In a study conducted by Deutsch et al., [5], microbubbles have resistance to low-pressure gradient differences, causing bubbles to erupt more quickly and easy to slip against the plate's surface. The cause does not happen a lot when using nanobubbles. Nanobubbles' characteristics guarantee the bubbles to endure the resistance of pressure difference, as discussed in Wang L. et al., [18]. In addition to the graph in Figure 4(b), it is clear that the reduction in skin friction coefficient begins to show stability with an increase in the percentage of drag reduction $82 \%$ with a maximum reduction ratio of skin friction coefficient 0.8704 . Finally, in Figure 4(c), the percentage of skin friction coefficient ratio has decreased. The decrease occurred because of fluid velocity flow in the experimental apparatus passing quickly.

Consequently, bubbles are too scattered in the test tank and hard to do their job as air lubrication is stated according to the data shown. Drag reduction has decreased again by $13 \%$ compared to the speed of $6 \mathrm{~ms}^{-1}<\mathrm{U}<13 \mathrm{~ms}^{-1}$. On the other hand, drag reduction still occurs at the speed of $14 \mathrm{~ms}^{-1}<\mathrm{U}$ $<20 \mathrm{~ms}^{-1}$, although the ratio of the skin friction coefficient only reaches a 0.75 maximum at $16 \mathrm{~ms}-1$. Notwithstanding, as a breakthrough, this study succeeded in maintaining drag efficiency up to $75 \%$ above the speed of $13 \mathrm{~ms}^{-1}$ compared to similar studies conducted by Madavan et al., [13]. 


\section{Conclusions}

Based on the results that was discussed in the previous session. The research can conclude three important points

i. When the fluid velocity is $1 \mathrm{~ms}-1<\mathrm{U}<6 \mathrm{~ms}-1$, the maximum drag reduction percentage is $60.5 \%$ due to the gas distribution ratio reduction, which requires time to collect under the flat plate and function as lubrication. Drag reduction at this speed can be seen in comparison with the results of the study of Murai et al., [15].

ii. The appropriate speed for using nanobubbles for a maximum drag reduction of $85 \%$ is found in fluid velocities in the range of $6 \mathrm{~ms}-1<\mathrm{U}<13 \mathrm{~ms}-1$. Compared to the results of the study of Deutsch et al., [5], and can maintain the lubricating effect of nanobubbles even though fluid flow rates are in the range of $14 \mathrm{~ms}-1<U<20 \mathrm{~ms}-1$ by $75 \%$ shown by Figure 5.

iii. Characteristics of bubbles that can maintain their shape despite pressure differences are useful for reducing resistance and increasing the reduction ratio of resistance.

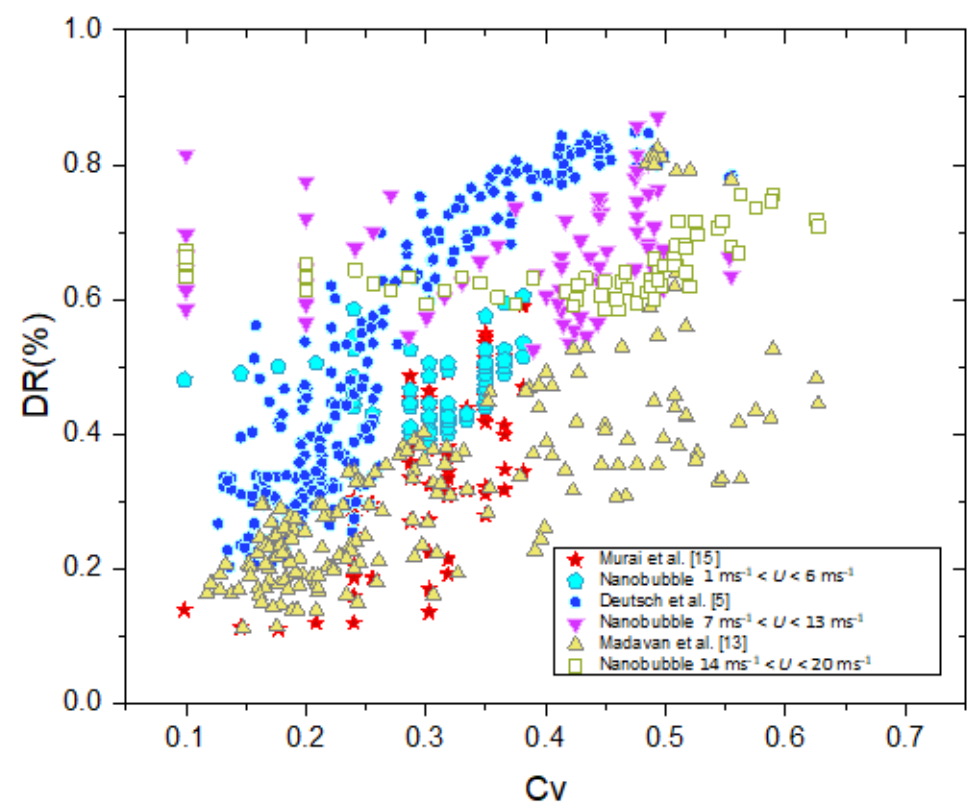

Fig. 5. Comparison of experimental results using bubbles as a lubrication method to reduce resistance or drag reduction on flat plates

\section{Acknowledgement}

The work is made possible because of the funding by Ministry of Research and Technology of the Republic of Indonesia, Penelitian Dasar 2020 (NKB- 2655/UN2. RST/HKP.05.00/2020).

\section{References}

[1] Sanders, Wendy C., Eric S. Winkel, David R. Dowling, Marc Perlin, and Steven L. Ceccio. "Bubble friction drag reduction in a high-Reynolds-number flat-plate turbulent boundary layer." Journal of Fluid Mechanics 552 (2006): 353. https://doi.org/10.1017/S0022112006008688

[2] McCormick, M. E., and R. Battacharyya. "Drag Reduction of a Submersible Hull by Electrolysis, Naval Engrs." (1973): 11-16. https://doi.org/10.1111/j.1559-3584.1973.tb04788.x 
[3] Aljallis, Elias, Mohammad Amin Sarshar, Raju Datla, Vinod Sikka, Andrew Jones, and Chang-Hwan Choi. "Experimental study of skin friction drag reduction on superhydrophobic flat plates in high Reynolds number boundary layer flow." Physics of fluids 25, no. 2 (2013): 025103. https://doi.org/10.1063/1.4791602

[4] Laberteaux, K. R., and S. L. Ceccio. "Partial cavity flows. Part 1. Cavities forming on models without spanwise variation." Journal of Fluid Mechanics 431 (2001): 1-41. https://doi.org/10.1017/S0022112000002925

[5] Deutsch, Steven, Michael Moeny, Arnold Fontaine, and Howard Petrie. "Microbubble drag reduction in rough walled turbulent boundary layers." In Fluids Engineering Division Summer Meeting, vol. 36967, pp. 665-673. 2003.

[6] Kodama, Yoshiaki, Akira Kakugawa, Takahito Takahashi, Satoru Ishikawa, Chiharu Kawakita, Takeshi Kanai, Yasuyuki Toda et al. "A Full-scale Experiment on Microbubbles for Skin Friction Reduction Using" SEIUN MARU"." Journal of the Society of Naval Architects of Japan 2002, no. 192 (2002): 1-13. https://doi.org/10.2534/ijasnaoe1968.2002.1

[7] Kawamura, Takafumi, Yasuhiro Moriguchi, Hiroharu Kato, Akira Kakugawa, and Yoshiaki Kodama. "Effect of bubble size on the microbubble drag reduction of a turbulent boundary layer." In Fluids Engineering Division Summer Meeting, vol. 36967, pp. 647-654. 2003. https://doi.org/10.1115/FEDSM2003-45645

[8] Utomo, A. S. A. "Nanobubbles interaction on flat plates affecting volumetric gas flux and local void ratio." Journal of Advanced Research in Fluid Mechanics and Thermal Sciences 69, no. 1 (2020): $137-147$. https://doi.org/10.37934/arfmts.69.1.137147

[9] Jang, Jinho, Soon Ho Choi, Sung-Mok Ahn, Booki Kim, and Jong Soo Seo. "Experimental investigation of frictional resistance reduction with air layer on the hull bottom of a ship." International Journal of Naval Architecture and Ocean Engineering 6, no. 2 (2014): 363-379. https://doi.org/10.2478/IJNAOE-2013-0185

[10] Lenaers, Peter, Qiang Li, Geert Brethouwer, Philipp Schlatter, and Ramis Örlü. "Rare backflow and extreme wallnormal velocity fluctuations in near-wall turbulence." Physics of fluids 24, no. 3 (2012): 035110. https://doi.org/10.1063/1.3696304

[11] Willert, Christian E., Christoph Cuvier, Jean-Marc Foucaut, Joachim Klinner, Michel Stanislas, Jean-Philippe Laval, S. Srinath et al. "Experimental evidence of near-wall reverse flow events in a zero pressure gradient turbulent boundary layer." Experimental Thermal and Fluid Science 91 (2018): 320-328. https://doi.org/10.1016/i.expthermflusci.2017.10.033

[12] Lin, Ping, Fu-li Wang, Liu Liu, and Qing He. "Characteristics of iron droplet ejection caused by gas bubble bursting under reduced pressure." Journal of Iron and Steel Research International 17, no. 1 (2010): 7-11. https://doi.org/10.1016/S1006-706X(10)60036-2

[13] Madavan, N. K., S. Deutsch, and C. L. Merkle. Measurements of local skin friction in a microbubble modified turbulent boundary layer. No. PSU/ARL-TM-84-136. PENNSYLVANIA STATE UNIV UNIVERSITY PARK APPLIED RESEARCH LAB, 1984. https://doi.org/10.1063/1.864620

[14] Kato, Hiroharu, Kento Miura, Hajime Yamaguchi, and Masaru Miyanaga. "Experimental study on microbubble ejection method for frictional drag reduction." Journal of marine science and technology 3, no. 3 (1998): 122-129. https://doi.org/10.1007/BF02492919

[15] Murai, Yuichi, Hiroshi Fukuda, Yoshihiko Oishi, Yoshiaki Kodama, and Fujio Yamamoto. "Skin friction reduction by large air bubbles in a horizontal channel flow." International journal of multiphase flow 33, no. 2 (2007): 147-163. https://doi.org/10.1016/j.ijmultiphaseflow.2006.08.008

[16] Latorre, Robert, Aaron Miller, and Richard Philips. "Micro-bubble resistance reduction on a model SES catamaran." Ocean engineering 30, no. 17 (2003): 2297-2309.

[17] Webster, W. (Ed.), 1992. Validation example-uncertainity analysis of a HSMV resistance test. Proc. 20 ${ }^{\text {th }}$ ITTC, Vol. 1 , San Fransisco, Sept. (1993): 394-402.

[18] Wang, Lei, Xiaojun Miao, Jafar Ali, Tao Lyu, and Gang Pan. "Quantification of oxygen nanobubbles in particulate matters and potential applications in remediation of anaerobic environment." ACS omega 3, no. 9 (2018): 1062410630. https://doi.org/10.1021/acsomega.8b00784 